\title{
An Assessment of Cardiac Risk Factors on Subclinical Hypothyroidism in Coronary Heart Disease Patients
}

\author{
Li Miao ${ }^{1}$, Xiyue Jing², Tingzhi Yan², Iruni Roshanie Abeysekera ${ }^{2}$, Ciri Chandana Raguthu ${ }^{2}$, Jin Ding ${ }^{2}$, Umar Iqbal ${ }^{2}$ \\ and Xiaomei Yao ${ }^{2 *}$
}

${ }^{1}$ Department of Cardiology, Third Central Hospital of Tianjin, Tianjin Institute of Hepatobiliary Disease, Tianjin Key Laboratory of Artificial Cell, Artificial Cell Engineering Technology Research Center of Public Health Ministry, Tianjin, China

${ }^{2}$ Tianjin Medical University, China

Submission: December 19, 2018; Published: January 24, 2019

*Corresponding author: Xiaomei Yao, Tianjin Medical University, Tianjin 300070, China

\begin{abstract}
Purpose: Subclinical hypothyroidism ( $\mathrm{SCH}$ ) is defined as a condition which shows an elevated serum thyroid-stimulating hormone (TSH) in the presence of normal free triiodothyronine (FT3) and tetraiodothyronine (FT4) levels. The effect of conventional factors for coronary heart disease (CHD) on the severity of SCH remains uncertain. Our aim was to evaluate the cardiac risk factors on various degrees of SCH in a cohort of CHD patients.
\end{abstract}

Methods: CHD patients were retrospectively divided into euthyroid, mild and severe SCH groups according to their thyroid functional status. Heath data from patients, including present and past history, results of blood biochemistry and ultrasound echocardiography were analyzed using univariate and multivariate logistic regression.

Results: Among the CHD patients with euthyroidism ( $=118)$, mild SCH ( $=70)$ and severe SCH (N=29), 5 of 13 related factors, including gender, smoking history, LVEF, E/A and antithyroid peroxidase autoantibody (anti-TPO) positive were significantly different among the three groups ( $\mathrm{p}<0.05)$. Interestingly, according to the results of univariate logistic regression, patients without smoking history were more likely to have mild SCH $(\mathrm{OR}=0.125, \mathrm{p}<0.001)$ and severe $\mathrm{SCH}(\mathrm{OR}=0.187, \mathrm{p}=0.009)$. Likewise, patients with low HDL-C level were more likely to have severe SCH $(\mathrm{OR}=0.401, \mathrm{p}=0.030)$. However, according to the results of multivariate logistic regression, females were more inclined to have mild $\mathrm{SCH}$ than males $(\mathrm{OR}=6.380, \mathrm{p}<0.001)$. And patients with anti-TPO positive were more likely to have severe $\mathrm{SCH}(\mathrm{OR}=6.427, \mathrm{p}=0.002)$.

Conclusion: Female CHD patients and an anti-TPO positive result were 2 independent factors related to SCH.

Keywords: Subclinical Hypothyroidism (SCH), Coronary Heart Disease (CHD), Risk Factors

Abbrevations: SCH: Subclinical Hypothyroidism; TSH: Thyroid-Stimulating Hormone; FT3: Free Triiodothyronine; FT4: Tetraiodothyronine; CHD: Coronary Heart Disease; SBP: Systolic Blood Pressure; DBP: Diastolic Blood Pressure; TC: Total Cholesterol; TG: Triglyceride; HDL-C HighDensity Lipoprotein-Cholesterol; LDL-C: Low-Density Lipoprotein-Cholesterol; BNP: B Type Natriuretic Peptide; LVEF: Left Ventricular Ejection Fraction; Tg Ab: Thyroglobulin Antibodies; TPO Ab: Thyroperoxidase Antibodies; AITD: Autoimmune Thyroid Disease; VIF: Variance Inflation Factors

\section{Introduction}

Subclinical hypothyroidism ( $\mathrm{SCH}$ ) is defined as elevated serum thyroid-stimulating hormone (TSH) in the presence of normal free triiodothyronine (FT3) and tetraiodothyronine (FT4) levels [1]. It is a relatively common condition with prevalence ranging from $4 \%$ to $15 \%$ in the general population, which may be interpreted in relation to the demographic, ethnic and lifestyle characteristics of the studied population [2]. Coronary heart disease (CHD) is a frequent cause of morbidity and mortality around the world and has classically been associated with related factors such as smoking history, diabetes, hypertension and dyslipidemia. Thyroid hormones have a significant impact on the heart function. It is reported that $\mathrm{SCH}$ is associated with an increased risk of CHD events and mortality, particularly in those with a TSH concentration of $10 \mathrm{mIU} / \mathrm{L}$ or greater [3]. Generally, it is recommended that thyroid hormone treatment be given to those individuals with SCH and TSH values $\geq 10 \mathrm{mIU} / \mathrm{L}$. Conversely, treatment of patients with $\mathrm{SCH}$ and TSH values $<10$ $\mathrm{mIU} / \mathrm{L}$ is quite controversial [4]. However, the way by which risk factors of CHD affect various degrees of SCH still remains unclear. In this study, our aim was to evaluate the cardiac risk factors on 
SCH in a cohort of CHD patients, which could potentially assist physicians in finding better strategies for their clinical problems for CHD patients complicated with SCH.

\section{Methods}

\section{Study design and eligibility criteria}

This retrospective study involving the laboratory results of previous cases, has been approved by the Third Central Hospital's medical ethics committee. Patient informed consent was also obtained during hospitalization. CHD patients with valid thyroid function test results from January 2013 to April 2018 in Cardiology Department of Tianjin Third Central Hospital were originally considered. CHD was based on the diagnostic criteria of the World Health Organization by searching for clinical symptoms, myocardial enzymes, ECG and coronary angiography (at least, stenosis of one major coronary artery $>50 \%$ ) [5]. Approval for the study was obtained from the Ethics Committee. Diabetes mellitus (Type 2) was determined by a biochemical test resulting in a fasting serum glucose level of at least $126 \mathrm{mg} /$ $\mathrm{dL}(7.0 \mathrm{mmol} / \mathrm{L})$ based on the criteria outlined by the World Health Organization (WHO), or the patient was on a prescribed drug regimen for diabetes mellitus (Type 2) [6]. Hypertension was defined as systolic blood pressure (SBP) > $140 \mathrm{mmHg}$ and/ or diastolic blood pressure (DBP) $\geq 90 \mathrm{mmHg}$ or treatment with anti-hypertensive medication [7]. 217 patients were finally enrolled after excluding those CHD patients with incomplete clinical records and those who were treated with anti-thyroid drugs, thyroxine, amiodarone or glucocorticoids. According to the thyroid functional status, the cases were divided into euthyroid group $(0.27 \mathrm{mIU} / \mathrm{L}<\mathrm{TSH} \leq 4.50 \mathrm{mIU} / \mathrm{L}, \mathrm{N}=118)$, mild SCH group (4.50 mIU / L < TSH $<10.00 \mathrm{mIU} / \mathrm{L}, \mathrm{N}=70$ ) and severe SCH group (TSH $\geq 10.00 \mathrm{mIU} / \mathrm{L}, \mathrm{N}=29$ ), with normal FT4 and FT3 levels.

\section{Biochemical and echocardiographic examination}

Fasting venous blood was collected for biochemical examinations. FT3, FT4, TSH, anti-thyroid peroxidase autoantibody (anti-TPO), total cholesterol (TC) and triglyceride (TG) kits were purchased from Roche Diagnostics $\mathrm{GmbH}$ (Roche Diagnostics GmbH, Mannheim, Germany), kits for the measurement of lipid profiles including high-density lipoproteincholesterol (HDL-C) and low-density lipoprotein-cholesterol (LDL-C) were bought from DiaSys (Diagnostic Systems GmbH, Holzheim, Germany). B type natriuretic peptide (BNP) kit was

Table 1: Association between Patients Characteristics and TSH levels. bought from Alere Triage (Alere $\mathrm{GmbH}$, Steinacherstrasse, Switzerland). All measurements were made by following the manufacturer's guidance. A color doppler ultrasonic diagnostic apparatus (Philips iE elite) was used to perform ultrasound echocardiography. Systolic function was evaluated according to the left ventricular ejection fraction (LVEF) (normal value $\geq$ $55 \%$ ) and diastolic function was evaluated according to the ratio of the maximum of diastolic early ventricular filling peak $\mathrm{E}$ to the maximum diastolic late ventricular filling peak $\mathrm{A}$ in the cardiac cycle (E/A).

\section{Statistics}

The SAS (Statistical Analysis Software, version 9.4) (SAS Institute Inc., Gary, NC, USA) was used for statistical analysis. Age, HDL-C, LDL-C, TC, TG, BNP and LVEF were quantitative variables, while the others were qualitative variables. Since the quantitative variables were not normally distributed, they were expressed using the median (IQR). The non-parametric Kruskal-Wallis test was used to compare the difference in the quantitative variables among the three groups. The qualitative variables corresponding to the three groups were compared by means of Chi-squared test. Univariate and multivariate logistic regression was used to find the related factors of mild or severe SCH. Stepwise selection was used with an entry criterion of 0.10 and removal criterion of 0.15 . Statistical significance was set at $\mathrm{P}<0.05$.

\section{Results}

\section{Characteristics of CHD patients classified into euthyroid, mild and severe SCH groups}

A total of 217 patients were divided into three groups according to thyroid function tests, the euthyroid group $[0.27$ $\mathrm{mIU} / \mathrm{L}, \mathrm{TSH} \leq 4.50 \mathrm{mIU} / \mathrm{L}, \mathrm{N}=118$ ), the mild SCH group (4.50 $\mathrm{mIU} / \mathrm{L}<\mathrm{TSH}<10.00 \mathrm{mIU} / \mathrm{L}, \mathrm{N}=70$ ), and the severe SCH group (TSH $\geq 10.00 \mathrm{mIU} / \mathrm{L}, \mathrm{N}=29$ ). The median ages were 66.50, 65.00 and 70.00 years old in the euthyroid, mild and severe SCH groups. The median LVEF values in the three groups were 0.56 , 0.58 , and 0.58 , respectively. A comparison of characteristics of CHD patients among the groups showed no significant difference in age, hypertension, diabetes mellitus, HDL-C, LDL-C, TC, TG and BNP ( $p>0.05$ ). Nevertheless, 5 of 13 factors, including gender, smoking history, LVEF, E/A and anti-TPO were statistically significantly different among the three groups $(\mathrm{p}<0.05)$ (Table 1).

\begin{tabular}{|c|c|c|c|c|c|c|}
\hline \multirow{2}{*}{ Variables } & Groups & Euthyroidism & $\begin{array}{c}\text { Mild Subclinical } \\
\text { Hypothyroidism }\end{array}$ & $\begin{array}{c}\text { Severe Subclini- } \\
\text { cal Hypothyroid- } \\
\text { ism }\end{array}$ & Statistics & P \\
\hline $\begin{array}{c}\text { Age [Median } \\
\text { (IQR)] }\end{array}$ & & $66.50(13.00)$ & $65.00(5.00)$ & $70.00(11.00)$ & 1.883 & 0.39 \\
\hline \multirow{2}{*}{ Gender [n (\%)] } & $\mathrm{M}$ & $61(51.69)$ & $8(11.43)$ & $9(31.03)$ & 31.29 & $<0.001$ \\
\cline { 2 - 6 } & $\mathrm{F}$ & $57(48.31)$ & $62(88.57)$ & $20(68.97)$ & & \multirow{2}{*}{} \\
\hline
\end{tabular}




\begin{tabular}{|c|c|c|c|c|c|c|}
\hline \multirow{2}{*}{$\begin{array}{c}\text { Hypertension [n } \\
\text { (\%)] }\end{array}$} & No & $32(27.12)$ & 27 (38.57) & 12 (41.38) & \multirow{2}{*}{3.758} & \multirow{2}{*}{0.153} \\
\hline & Yes & 86 (72.88) & $43(61.43)$ & 17 (58.62) & & \\
\hline \multirow{2}{*}{$\begin{array}{c}\text { Diabetes mellitus } \\
{[\mathrm{n}(\%)]}\end{array}$} & No & $86(72.88)$ & 55 (78.57) & 23 (79.31) & \multirow{2}{*}{1.024} & \multirow{2}{*}{0.599} \\
\hline & Yes & $32(27.12)$ & 15 (21.43) & $6(20.69)$ & & \\
\hline \multirow{2}{*}{$\begin{array}{c}\text { Smoking history } \\
\text { [n (\%)] }\end{array}$} & No & 73 (61.86) & $65(92.86)$ & $26(89.66)$ & \multirow{2}{*}{26.458} & \multirow{2}{*}{$<0.001$} \\
\hline & Yes & 45 (38.14) & $5(7.14)$ & $3(10.34)$ & & \\
\hline $\begin{array}{l}\text { HDL-C [Median } \\
\text { (IQR)] }\end{array}$ & & $1.14(0.23)$ & $1.08(0.67)$ & $1.00(0.33)$ & 2.089 & 0.352 \\
\hline $\begin{array}{c}\text { LDL-C [Median } \\
\text { (IQR)] }\end{array}$ & & $2.96(1.43)$ & $2.70(0.94)$ & $2.62(0.66)$ & 3.353 & 0.187 \\
\hline $\begin{array}{l}\text { TC [Median } \\
\text { (IQR)] }\end{array}$ & & 4.89 (1.19) & $4.65(1.11)$ & 4.27 (1.51) & 1.871 & 0.392 \\
\hline $\begin{array}{l}\text { TG [Median } \\
\text { (IQR)] }\end{array}$ & & $1.49(1.03)$ & $1.54(1.07)$ & $1.36(1.04)$ & 0.238 & 0.888 \\
\hline $\begin{array}{l}\text { BNP [Median } \\
\text { (IQR)] }\end{array}$ & & $25.10(189.15)$ & $27.80(224.50)$ & $31.10(805.5)$ & 2.31 & 0.315 \\
\hline $\begin{array}{l}\text { LVEF [Median } \\
\text { (IQR)] }\end{array}$ & & $0.56(0.08)$ & $0.58(0.04)$ & $0.58(0.05)$ & 13.677 & 0.001 \\
\hline \multirow{2}{*}{ E/A [n (\%)] } & Normal & 35 (57.38) & $25(35.71)$ & $14(48.28)$ & \multirow{2}{*}{6.212} & \multirow{2}{*}{0.045} \\
\hline & Abnormal & $26(42.62)$ & 45 (64.29) & $15(51.72)$ & & \\
\hline \multirow{2}{*}{$\begin{array}{c}\text { Anti-TPO positive } \\
\text { [n (\%)] }\end{array}$} & Normal & 112 (94.92) & 59 (84.29) & 18 (62.07) & \multirow{2}{*}{23.074} & \multirow{2}{*}{$<0.001$} \\
\hline & Abnormal & $6(5.08)$ & $11(15.71)$ & 11 (37.93) & & \\
\hline
\end{tabular}

\section{Univariate logistic regression}

Table 2: Univariate logistic regression for the TSH levels.

\begin{tabular}{|c|c|c|c|c|c|c|c|c|c|c|}
\hline \multirow{2}{*}{ Variables } & \multicolumn{5}{|c|}{ Mild Subclinical Hypothyroidism (Ref=Normal) } & \multicolumn{5}{|c|}{ Severe Subclinical Hypothyroidism (Ref=Normal) } \\
\hline & $\beta$ & SE & Wald $\chi^{2}$ & OR $(95 \% \mathrm{CI})$ & $\mathbf{P}$ & $\beta$ & SE & Wald $\chi^{2}$ & OR $(95 \% \mathrm{CI})$ & $\mathbf{P}$ \\
\hline Age & 0.002 & 0.015 & 0.018 & $\begin{array}{c}1.002 \\
(0.973,1.032)\end{array}$ & 0.894 & 0.02 & 0.021 & 0.841 & $\begin{array}{c}1.020(0.978 \\
1.063)\end{array}$ & 0.359 \\
\hline $\begin{array}{l}\text { Gender } \\
\text { (Ref=M) }\end{array}$ & 2.116 & 0.418 & 25.564 & $\begin{array}{c}8.294 \\
(3.653,18.832)\end{array}$ & $<0.001$ & 0.866 & 0.442 & 3.848 & $\begin{array}{l}2.378(1.001 \\
5.652)\end{array}$ & 0.049 \\
\hline $\begin{array}{l}\text { Hyper- } \\
\text { tension } \\
\text { (Ref=No) }\end{array}$ & -0.523 & 0.321 & 2.654 & $\begin{array}{c}0.593(0.316 \\
1.112)\end{array}$ & 0.103 & -0.64 & 0.43 & 2.217 & $\begin{array}{c}0.527(0.227 \\
1.225)\end{array}$ & 0.137 \\
\hline $\begin{array}{l}\text { Diabetes } \\
\text { mellitus } \\
\text { (Ref=No) }\end{array}$ & -0.311 & 0.357 & 0.756 & $\begin{array}{c}0.733(0.364 \\
1.477)\end{array}$ & 0.385 & $\begin{array}{l}-0.3 \\
55\end{array}$ & 0.503 & 0.498 & $\begin{array}{c}0.701(0.262 \\
1.879)\end{array}$ & 0.48 \\
\hline $\begin{array}{l}\text { History } \\
\text { of smoke } \\
\text { (Ref=No) }\end{array}$ & -2.081 & 0.501 & 17.235 & $\begin{array}{c}0.125(0.047 \\
0.333)\end{array}$ & $<0.001$ & -1.676 & 0.639 & 6.887 & $\begin{array}{c}0.187(0.054 \\
0.654)\end{array}$ & 0.009 \\
\hline HDL-C & -0.418 & 0.311 & 1.81 & $\begin{array}{c}0.658(0.358 \\
1.211)\end{array}$ & 0.179 & -0.914 & 0.422 & 4.696 & $\begin{array}{c}0.401(0.176 \\
0.916)\end{array}$ & 0.03 \\
\hline LDL-C & -0.369 & 0.305 & 1.463 & $\begin{array}{c}0.691(0.380 \\
1.258)\end{array}$ & 0.226 & -0.415 & 0.417 & 0.989 & $\begin{array}{c}0.660(0.292 \\
1.496)\end{array}$ & 0.32 \\
\hline $\mathrm{TC}$ & -0.024 & 0.329 & 0.005 & $\begin{array}{c}0.976(0.513 \\
1.859)\end{array}$ & 0.942 & -0.322 & 0.478 & 0.454 & $\begin{array}{c}0.725(0.284 \\
1.849)\end{array}$ & 0.501 \\
\hline $\mathrm{TG}$ & -0.006 & 0.312 & 0.0004 & $\begin{array}{c}0.994(0.539 \\
1.832)\end{array}$ & 0.984 & 0.028 & 0.427 & 0.004 & $\begin{array}{c}1.028(0.445, \\
2.376)\end{array}$ & 0.949 \\
\hline BNP & -0.446 & 0.372 & 1.44 & $\begin{array}{c}0.640(0.309 \\
1.326)\end{array}$ & 0.23 & -0.537 & 0.534 & 1.009 & $\begin{array}{c}0.585(0.205 \\
1.666)\end{array}$ & 0.315 \\
\hline LVEF & 7.639 & 2.516 & 9.218 & $\begin{array}{c}>999.999(14.993 \\
>999.999)\end{array}$ & 0.002 & 4.758 & 3.103 & 2.351 & $\begin{array}{c}116.45(0.266 \\
>999.999)\end{array}$ & 0.125 \\
\hline
\end{tabular}




\begin{tabular}{|c|c|c|c|c|c|c|c|c|c|c|}
\hline $\begin{array}{c}\text { E/A } \\
\text { (Ref=Nor- } \\
\text { mal) }\end{array}$ & 0.885 & 0.36 & 6.059 & $2.423(1.198,4.90)$ & 0.014 & 0.366 & 0.453 & 0.653 & $\begin{array}{c}1.442(0.594 \\
3.503)\end{array}$ & 0.419 \\
\hline $\begin{array}{c}\text { Anti-TPO } \\
\text { positive } \\
\text { (Ref=Nor- } \\
\text { mal) }\end{array}$ & 1.247 & 0.532 & 5.487 & $3.180(1.226,9.88)$ & 0.019 & 2.434 & 0.568 & 18.399 & $\begin{array}{c}11.407 \\
(3.751, \\
34.6)\end{array}$ & $<0.001$ \\
\hline
\end{tabular}

Table 2 depicts the results of the univariate logistic regression. According to variant TSH levels, the univariate logistic regression analysis demonstrated statistical significance for gender, smoking history, LVEF, E/A and anti-TPO between the mild SCH group and the euthyroid group. With regards to gender, when compared with males, females were more likely to be mild SCH patients (OR: 8.294, 95\% CI: 3.653-18.832). Patients without smoking history were more likely to have mild SCH (OR: 0.125, 95\% CI: 0.047-0.333). LVEF (OR: >999.999, 95\% CI: 14.993->999.999) and E/A (OR: 2.423, 95\% CI: 1.198-4.902) were both related factors for mild $\mathrm{SCH}$, while patients with antiTPO positive were more likely to have mild SCH (OR: 3.180, 95\% CI: 1.226-9.881).

Between the severe SCH group and the euthyroidism group, differences in gender, smoking history, HDL-C and an antiTPO positive result were all statistically significant $(\mathrm{p}<0.05)$. Regarding the gender, when compared with males, females were more likely to be severe SCH patients (OR: 2.378, 95\% CI:
1.001-5.652). Patients without smoking history were more likely to have severe SCH (OR: 0.187, 95\% CI: 0.054-0.654). Patients with lower HDL-C values were more likely to have severe SCH (OR: 0.401, 95\% CI: 0.176-0.916). An anti-TPO positive result correlated with an increased risk of severe SCH (OR: 11.407, 95\% CI: 3.751-34.693) (Table 2).

\section{Multivariate logistic regression}

According to the results of univariate logistic regression, variables including gender, smoking history, HDL-C, LVEF, E/A and anti-TPO positive result were all placed into the multivariate logistic regression. Table 3 depicts the results of the multivariate logistic regression. Gender and an anti-TPO positive result were 2 independent factors related to SCH. When compared with males, females were more likely to be mild SCH patients (OR: 6.380, 95\% CI: 2.608-15.608). An anti-TPO positive result correlated with an increased risk of severe SCH (OR: 6.427, 95\% CI: 1.95221.157) (Table 3).

Table 3: Multivariate logistic regression for the TSH levels.

\begin{tabular}{|c|c|c|c|c|c|c|c|c|c|c|}
\hline \multirow{2}{*}{ Variables } & \multicolumn{5}{|c|}{ Mild Subclinical Hypothyroidism (Ref=Normal) } & \multicolumn{5}{|c|}{ Severe Subclinical Hypothyroidism (Ref=Normal) } \\
\hline & $\beta$ & SE & Wald $\chi^{2}$ & OR $(95 \% \mathrm{CI})$ & $\mathbf{P}$ & $\beta$ & SE & Wald $\chi^{2}$ & OR $(95 \% \mathrm{CI})$ & $\mathbf{P}$ \\
\hline Intercept & -3.149 & 0.832 & 14.333 & - & 0.0002 & -1.882 & 0.854 & 4.859 & - & 0.028 \\
\hline $\begin{array}{c}\text { Gender } \\
\text { (Ref=Male) }\end{array}$ & 1.853 & 0.456 & 16.485 & $\begin{array}{c}6.38(2.608 \\
15.608)\end{array}$ & $<0.001$ & 0.471 & 0.501 & 0.884 & $\begin{array}{c}1.602(0.600 \\
4.275)\end{array}$ & 0.347 \\
\hline $\begin{array}{l}\text { Anti-TPO } \\
\text { positive } \\
\text { (Ref=Nor- } \\
\text { mal) }\end{array}$ & 0.555 & 0.592 & 0.879 & $\begin{array}{c}1.742(0.546 \\
5.556)\end{array}$ & 0.349 & 1.861 & 0.608 & 9.367 & $\begin{array}{c}6.427(1.952 \\
21.157)\end{array}$ & 0.002 \\
\hline
\end{tabular}

\section{Discussion}

In this study, we demonstrated that females were more likely to be $\mathrm{SCH}$ patients compared with males. It was reported that $0.5 \%-2.5 \%$ of women in their childbearing age have $\mathrm{SCH}$, thus leading to an increased risk of miscarriage [8]. According to Cooper et al. [9]. from census data, it can be calculated that approximately 4.4 million men and 9.6 million women have SCH [9]. Pedersen et al. [10]. performed a cross-sectional study of thyroperoxidase antibodies (TPO $\mathrm{Ab}$ ) and thyroglobulin antibodies ( $\mathrm{Tg} \mathrm{Ab}$ ) in 4,649 Danish subjects. The presence of both antibodies was more frequent in females and showed a direct correlation with SCH [10]. The reason for female predominance still remains unclear. The increase in the serum thyroxine-binding globulin concentration is induced by estrogen in pregnant women. The administration of estrogen causes dosedependent increases in the serum concentrations of thyroxine- binding globulin and thyroxine in women with normal thyroid function. While some women with hypothyroidism receiving thyroxine therapy needed more thyroxine when they received estrogen therapy, a change caused by an estrogen-induced increase in the serum concentration of thyroxine-binding globulin [11].

The anti-TPO positive result was shown as an independent related factor of $\mathrm{SCH}$ in the present study, especially in CHD patients with severe SCH. Autoimmune thyroid disease (AITD) is characterized by the presence of thyroid antibodies, specifically thyroid peroxidase antibodies (anti-thyroid peroxidase, antiTPO). AITD development occurs due to a failure of immune tolerance and reactivity to thyroid auto-antigens [12]. SCH is characterized by the elevated TSH. TSH at various concentrations could stimulate the immune system by increasing the proliferative 
response of lymphocytes and activity of natural killer cells. TSH concentrations in anti-TPO-positive women were approximately twice that of anti-TPO-negative women [13].

We reported that the patients without smoking history were more likely to have both mild and severe SCH in present study. Knudsen $\mathrm{N}$ et al. [14] investigated 4649 subjects in Denmark by multivariate regression models, a lower prevalence of $\mathrm{SCH}$ was found among smokers than among non-smokers [14], which is consistent with our results. This can be explained by an association between $\mathrm{SCH}$ and tobacco smoking, the latter of which is a preventive effect mediated by the blocking of iodine uptake and organification in the thyroid by thiocyanate, which is a degradation product of cyanide in tobacco smoke. It is well known that the prevalence of cigarette smoking is lower in females than in males. In order to investigate whether the effect of smoking on SCH may attribute to the gender difference, we calculated the variance inflation factors (VIF) of the two factors for the problem of multicollinearity. The VIFs of the factors of gender and smoking history were 2.243 and 3.293, respectively. According to Hossain's study [15], $0<\mathrm{VIF}<5$ means that the multicollinearity problem does not exist; $5 \leq \mathrm{VIF} \leq 10$ means that a moderate multicollinearity problem exists; and VIF $>10$ means that a serious multicollinearity problem exists. In our study, the VIFs of the factors of gender and smoking were both lower than 5. Therefore, there was no evidence of a multicollinearity problem in our independent variables.

In addition, we demonstrated that CHD patients with lower HDL-C levels were more likely to have severe SCH. Epidemiological studies have demonstrated that HDL-C level is a strong, independent, and inverse related factor for CHD, thus the CHD risk is lower in people with higher HDL-C. HDL-C has been shown to be associated with preventing against CHD through possible mechanisms of reverse cholesterol transport and reduction of low-density lipoprotein oxidative stress [16]. Reducing LDL cholesterol levels has been demonstrated to be independently associated with favorable outcomes in CHD secondary prevention [17]. This is primarily due to the effects of HDL on preventing atherosclerosis by promoting cholesterol efflux, reducing oxidation, attenuating vascular inflammation and improving vascular endothelial function [18].

The relation between HDL level and SCH is still controversial. A Meta-Analysis study included a total 40516 participants whose serum HDL-C levels were measured. Three of these studies reported significant lower HDL-C levels in SCH patients and 1 reported significant higher level compared with euthyroid participants [19]. HDL has been reported to improve the endothelial dysfunction by stimulating NO release and inducing vasodilation in the isolated aorta, and therefore protects the endothelial function. SCH may induce endothelial dysfunction by increasing lipid disorders [20]. There was a significant correlation between SCH and decreased HDL level. Participants with SCH had significantly lower HDL levels than the control group regardless of age group and gender [21]. The activities of hepatic lipase, lecithin cholesterol acyl transferase, and ATPbinding cassette transporter were decreased in SCH patients, which may lead to lower HDL-C levels. Polymorphisms of genes and osteocalcin concentration may also affect the metabolism of HDL-C [19].

Furthermore, we demonstrated significant differences in LVEF and E/A among the three groups when the characteristics of CHD patients were compared. LVEF is the stroke volume divided by left ventricular end-diastolic volume, usually expressed as a percentage and used to assess the cardiac contractility, as well as to further evaluate both the left ventricular and systolic functions of the heart. It was reported that SCH is associated with impaired left ventricular diastolic function at rest, systolic dysfunction on attempt, and elevated possibility for atherosclerosis and myocardial infarction [23]. The E/A is a ratio of early to late ventricular filling velocities. An abnormal E/A ratio can signify diastolic dysfunction due to impaired relaxation. Consequently, it results in a state of low cardiac output with decreased heart rate and stroke volume [23]. A reduced coronary artery flow is a hallmark for microvascular disease of the coronary artery and found in patients with $\mathrm{SCH}$. A possible mechanism could be that TSH can control lipid homeostasis, which potentially modulates the cardiovascular conditions. The TSH level is closely correlated with the carotid intima-media thickness, which is a known marker of early atherosclerotic changes [24].

\section{Conclusion}

In conclusion, 5 of 13 factors, including gender, smoking history, LVEF, E/A and an anti-TPO positive result were all significantly different among the three groups of euthyroidism, mild and severe SCH categories in the present study. Females were more likely to have mild SCH than males. And patients with an anti-TPO positive result were more likely to have severe SCH. Patients without a smoking history were more likely to have mild and severe SCH. Likewise, patients with low HDL-C level were more likely to have severe $\mathrm{SCH}$.

\section{Acknowledgement}

This work is supported by Tianjin Science \& Technology Council Grant of China (grant number 16JCYBJC26100), National Natural Science Foundation of China (grant number 81874257). Li Miao and Xiyue Jing authors are equally contributed to this work

\section{References}

1. Javed Z, Sathyapalan T (2016) Levothyroxine treatment of mild subclinical hypothyroidism: a review of potential risks and benefits. Ther Adv Endocrinol Metab 7(1): 12-23.

2. Hollowell JG, Staehling NW, Flanders WD, Hannon WH, Gunter EW et al. (2002) Serum TSH, T(4), and thyroid antibodies in the United States population (1988 to 1994): National Health and Nutrition Examination Survey (NHANES III). J Clin Endocrinol Metab 87(2): 489-499.

3. Rodondi Nicolas, Bauer Douglas C, Cappola Anne R, Cornuz Jacques, Robbins John, et al. (2008) Subclinical thyroid dysfunction, cardiac function, and the risk of heart failure: The Cardiovascular Health study, J Am Coll Cardiol 52: 1152-1159. 
4. Weiss IA, Bloomgarden N, Frishman WH (2011) Subclinical hypothyroidism and cardiovascular risk: recommendations for treatment. Cardiol Rev 19: 291-299.

5. Wang H, Yuan Y, Song L, Qiu G, Lai X, et al. (2017) Association between education and the risk of incident coronary heart disease among middle-aged and older Chinese: the Dongfeng-Tongji Cohort. Sci Rep $7(1): 776$.

6. Alberti KG, Zimmet PZ (1998) Definition, diagnosis and classification of diabetes mellitus and its complications. Part 1: diagnosis and classification of diabetes mellitus provisional report of a WHO consultation. Diabet Med 15(7): 539-553.

7. Newhouse SJ, Wallace C, Dobson R, Mein C, Pembroke J, et al. (2005) Haplotypes of the WNK1 gene associate with blood pressure variation in a severely hypertensive population from the British Genetics of Hypertension study. Hum Mol Genet 14(13): 1805-1814.

8. Casey BM, Dashe JS, Wells CE, McIntire DD, Byrd W (2005) Subclinical hypothyroidism and pregnancy outcomes. Obstet Gynecol 105(2): 239245

9. Cooper DS, Ridgway EC (2002) Thoughts on Prevention of Thyroid Disease in the United States. Thyroid 12: 925-929.

10. Pedersen IB, Knudsen N, Jørgensen T, Perrild H, Ovesen L, et al. (2003) Thyroid peroxidase and thyroglobulin autoantibodies in a large survey of populations with mild and moderate iodine deficiency. Clin Endocrinol (Oxf) 58(1): 36-42.

11. Arafah BM (2001) Increased need for thyroxine in women with hypothyroidism during estrogen therapy. N Engl J Med 344(23): 17431749.

12. Mayer O Jr, Simon J, Filipovský J, Plásková M, Pikner R (2006) Hypothyroidism in coronary heart disease and its relation to selected risk factors. Vasc Health Risk Manag 2(4): 499-506.

13. Pearce EN, Oken E, Gillman MW, Lee SL, Magnani B, et al. (2008) Association of first-trimester thyroid function test values with thyroperoxidase antibody status, smoking, and multivitamin use. Endocr Pract 14(1): 33-39.

14. Knudsen N, Bülow I, Laurberg P, Perrild H, Ovesen L, et al. (2002) currence of thyroid multinodularity and low occurrence of subclinical hypothyroidism among tobacco smokers in a large population study. J Endocrinol 175: 571-576.
15. Hossain MG, Saw A, Alam R, Ohtsuki F, Kamarul T (2013) Multiple regression analysis of anthropometric measurements influencing the cephalic index of male Japanese university students. Singapore Med J 54(9): 516-20.

16. Tehrani DM, Gardin JM, Yanez D, Hirsch CH, Lloyd-Jones DM, et al. (2013) Impact of inflammatory biomarkers on relation of highdensity lipoprotein-cholesterol with incident coronary heart disease: cardiovascular Health Study. Atherosclerosis 231(2): 246-251.

17. Cai A, Li X, Zhong Q, Li M, Wang R, et al. (2016) Associations of high HDL cholesterol level with all-cause mortality in patients with heart failure complicating coronary heart disease. Medicine (Baltimore) 95(28): e3974.

18. Rosenson RS, Brewer HB, Ansell B, Barter P, Chapman MJ, et al. (2013) Translation of high-density lipoprotein function into clinical practice: current prospects and future challenges. Circulation 128(11): 12561267.

19. Liu XL, He S, Zhang SF, Wang J, Sun XF, et al. (2014) Alteration of lipid profile in subclinical hypothyroidism: a meta-analysis. Med Sci Monit 20: 1432-41.

20. Lu M, Yang CB, Gao L, Zhao JJ (2015) Mechanism of subclinical hypothyroidism accelerating endothelial dysfunction (Review). Exp Ther Med 9(1): 3-10.

21. Rastgooye Haghi A, Solhjoo M, Tavakoli MH (2017) Correlation Between Subclinical Hypothyroidism and Dyslipidemia. Iran J Pathol 12(2): 106-111.

22. Lai Y, Wang J, Jiang F, Wang B, Chen Y, et al. (2011) The relationship between serum thyrotropin and components of metabolic syndrome. Endocr J 58(1): 23-30.

23. Rader DJ, Hovingh GK (2014) HDL and cardiovascular disease. Lancet 384: 618-625.

24. Paavola T, Kuusisto S, Jauhiainen M, Kakko S, Kangas-Kontio T, et al. (2017) Impaired HDL2-mediated cholesterol efflux is associated with metabolic syndrome in families with early onset coronary heart disease and low HDL-cholesterol level. PloS One 12(2): e0171993.

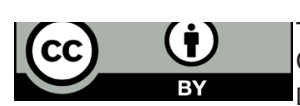

This work is licensed under Creative Commons Attribution 4.0 Licens DOI: $10.19080 / J E T R .2019 .04 .555629$

Your next submission with Juniper Publishers
will reach you the below assets
- Quality Editorial service
- Swift Peer Review
- Reprints availability
- E-prints Service
- Manuscript Podcast for convenient understanding
- Global attainment for your research
- Manuscript accessibility in different formats
( Pdf, E-pub, Full Text, Audio)
- Unceasing customer service
Track the below URL for one-step submission
https://juniperpublishers.com/online-submission.php

